\title{
Strategic adaptation to new electoral systems
}

\author{
PETER SELB \\ Department of Politics and Public Administration, University of Konstanz, Germany
}

\begin{abstract}
How quickly, to what extent and under what conditions do voters and elites adapt to new electoral institutions in order to not waste their votes and effort on hopeless competitors? A latent-curve model of strategic adaptation is developed and fitted to district-level election data from Spain. The extent of strategic adaptation is generally found to vary with the strength of the electoral system. However, grave ethnic tensions are demonstrated to seriously retard adaptation even under favourable institutional conditions.
\end{abstract}

Keywords: electoral coordination; strategic voting; dynamics; Spain

\section{Introduction}

The striking failures of supposedly proportional electoral systems in a number of new democracies actually to ensure parliamentary inclusiveness have stunned pundits and scholars alike. To name some drastic examples, a staggering 61 per cent of Georgian voters gave their votes to parties that failed to reach the national 5 per cent threshold at the 1995 parliamentary election. In the same year, Russia's Duma elections left 49 per cent of the voters unrepresented, although the legal threshold for securing a seat in the national assembly was only 7 per cent (Shvetsova 1999). Other instances abound (Dawisha \& Deets 2006) and have raised worries that the apparent inability of political elites to coordinate on promising candidates and party lists, and of voters to concentrate their votes on the viable alternatives, poses a potential threat to several aspects of democratic consolidation, including the development of a stable party system, the prevention of dominant parties and the representativeness of government policy (Cox 1997; Duch \& Palmer 2002; Horowitz \& Browne 2005; Mainwaring 1998).

In response to such events, scholars of elections and political representation have started to ask to what extent, at what pace and under what conditions political elites and voters manage to adapt to new electoral institutions (e.g., Duch \& Palmer 2002; Gschwend 2007; Horowitz \& Browne 2005; Moser \& Scheiner 2009; Tavits \& Annus 2006; Van der Weyden \& Meuleman 2008), and 
what happens if they fail to do so (e.g., Bielasiak 2005; Birch 2005; Bohrer 1997; Shvetsova 2002; Tavits 2008). These studies have contributed to the literatures on electoral systems and strategic voting in at least three significant ways. First, they did away with the popular misconception that varying amounts of votes lost during the process of vote-seat transformation are constitutive features of particular electoral systems, with single-member plurality (SMP) systems inevitably generating higher amounts of wasted votes than proportional representation (PR) and mixed systems. ${ }^{1}$ Obviously, these findings must dampen the hopes of 'electoral engineers' for strong institutional determinisms that would make the outcomes of newly designed electoral systems easily predictable. Second, these studies demonstrated that equilibria where parties and voters successfully coordinate on the viable alternatives are approached (if at all) much more slowly than many standard models of strategic voting would have one expect. ${ }^{2}$ Finally, these studies have pinpointed the enormous differences with respect to many indicators of successful strategic adaptation observable among new democracies.

At the same time, previous research often suffers from some drawbacks. On the one hand, the majority of these studies quite naturally focuses on countries from the most recent wave of democratisation and is therefore limited to the observation of at most a handful of elections. Such short time frames are probably ill-suited when one wishes to discern the full dynamics of strategic adaptation. Partly a consequence of the short time horizons, the dynamics many of the previous empirical models imply are overly simplistic. Scholars usually seek evidence of strategic adaptation by specifying an unconditional linear time trend among the covariates (e.g., Gschwend 2007; Moser \& Scheiner 2009; Tavits \& Annus 2006; Van der Weyden \& Meuleman 2008) - a less than optimal strategy for modeling almost inevitably non-linear and presumably conditional convergence processes toward equilibria that may differ among countries and electoral systems. Finally, many previous studies of strategic adaptation operate at the national level of analysis. However, as most electoral laws divide countries into districts where at least part of the parliamentary seats are allocated, incentives for strategic behaviour may also, or even primarily, arise at the level of districts. ${ }^{3}$ In the absence of district-specific knowledge, it is therefore extremely difficult to determine who (in the case of survey-based studies, e.g., Duch \& Palmer 2002) or what share of the electorate (in analyses of aggregate election outcomes, e.g., Tavits \& Annus 2006) actually wasted their votes on hopeless options.

In the present study, a novel latent-curve model of strategic adaptation is developed that heavily draws on Cox's (1997) strategic voting game with incomplete information. The model is then fitted to district-level election results from Spain. Spain seems a particularly attractive empirical case to test 
propositions on the conditions of successful adaptation to new electoral systems. First, due to its longer democratic experience, it allows for the observation of ten national elections since democratic transition in 1977 - a period seemingly long enough for strategic adaptation to materialise even under adverse conditions. Second, while formally a PR system, the Spanish electoral law divides the country into 52 constituencies where all the parliamentary seats are allocated, ranging from single-member districts (SMDs) to large districts with 35 seats, and therefore resembles the manifold institutional arrangements usually to be found in cross-national comparisons alone. Third, Spanish society is divided along strong regionally based political cleavages, which allows one to study the long-term interplay between institutional and social structures in shaping political behaviour.

\section{Conditions for successful adaptation}

Successful adaptation to new electoral institutions requires political elites to negotiate on promising candidates and party lists - for example, by withdrawing weak competitors, by running joint lists or candidacies, and ultimately, by party mergers. If they fail to do so, voters are expected to desert the hopeless candidates and lists in favour of less preferred but more viable alternatives. In other words, successful adaptation requires elites to coordinate, and voters to vote strategically. Cox (1997: 73-80) clearly explicates the fundamental conditions for elites and voters to behave that way. First, elites and voters must be short-term instrumentally motivated - that is, they must be concerned about who is winning in the present election only. Second, elites and voters must have common expectations about who is viable given the electoral systems' constraints and the distribution of the voters' preferences, otherwise it is impossible to decide on whom to coordinate. Third, elites and voters must have strict preferences among the competitors other than their own or most preferred party since strategically withdrawing or deserting a weak competitor in favour of a more promising choice will hardly be an option if one were indifferent about the viable alternatives. Narrative evidence from interviews with party leaders in Spain suggests that these conditions were hardly met in the early 1980s. As Gunther (1989: 855) puts it:

[A] significant number of key elites... placed other concerns above short-term maximization of parliamentary representation. Among those concerns were personal animosities; the desire to respect the traditions of their party and the integrity of the party institution itself; perceived ideological or programmatic incompatibility with potential coalition 
partners; concern over how certain party system configurations might threaten the stability of the democratic regime; and the desire to avoid repeating the mistakes of the past.

This section systematically investigates the extent to which these conditions will be met, particularly in new democracies.

\section{Information requirements}

Under a newly established electoral system, elites and voters have to form expectations about the system's constraints - that is, the vote shares required to gain seats and about the distribution of voter preferences. While the former is basically an arithmetic exercise presuming knowledge of the number of seats to be allocated in a particular district, electoral formulas, corrective mechanisms at higher electoral tiers and eventual legal thresholds, the latter task requires situational information either from current polls, news analyses, candidate statements (Black 1978; Cox 1994, 1997; Fey 1997), interpersonal communication (Clough 2007) or from the 'electoral histories' of candidates and parties - that is, previous election results (Cox 1997; Gschwend 2007; Lago 2008). ${ }^{4}$ How quickly voters and elites adapt to new institutions is then a function of the amount of information available, and of how efficiently this information is put to use.

Previous research suggests that political elites in new democracies largely proceed in a trial-and-error manner, thus relying on electoral histories rather than sitting down with a pocket calculator and devising optimal strategies based on precise knowledge of system constraints and up-to-date polling information (Reed 1990). For instance, while pre-election polling information has been available in Spain from the founding election in 1977, even national election forecasts were quite inaccurate in the beginning. In contrast, districtlevel forecasts have only been available from 1986 (Granados 2005). Trial-anderror learning of elites and voters generally suggests a self-reinforcing, albeit slowly moving, process of strategic adaptation to new electoral systems (H1). At the outset of this process, neither elites nor voters fully understand how the electoral system will work out. Moreover, electoral histories as one primary source of information are by definition unavailable. Strategic coordination and voting can hardly be expected at this stage. For the Spanish case, Gunther (1989: 854) concludes from a series of interviews with national party officials in the early 1980s that 'while nearly all party leaders were fully aware of the representational biases inherent in the Spanish electoral law, some key actors either had inaccurate information regarding their likely electoral support or 
intentionally misrepresented their levels of electoral appeal in the course of bargaining with potential coalition partners'.

As experience with the systems' mechanics and retrospective information accumulates over subsequent elections, however, the adaptive process is set into motion. In turn, as elites and voters start to behave strategically, thereby reducing the number of competitors to a more and more stable set of alternatives (i.e., party system), coordination gets easier (see Clough 2007) and election results become even more informative for future elections (Cox \& Shugart 1996). The following paragraphs will discuss potential qualifications to this so far unconditional model of adaptation to new electoral institutions.

\section{Institutional constraints}

Many authors consider increasing district magnitude as the prime culprit impeding strategic adaptation (e.g., Leys 1959; Sartori 1968; Cox 1994, 1997; Cox \& Shugart 1996). As the number of seats to be allocated in a district rises, so the argument goes, the vote shares required to change the seat distribution get smaller and the information accuracy needed to become confident that a particular candidate or list really is out of the running goes up. For example, in an SMP district where three parties are competing with expected vote shares of approximately 50,35 and 15 per cent, it is quite clear that Party 3 has no chance and should therefore be deserted by its voters in favour of either Party 1 or 2 . In a five-member district under d'Hondt, ${ }^{5}$ Party 3 would still go away empty-handed given the expected vote shares. However, an additional 2 per cent of the votes would suffice for Party 3 to conquer Party 1's final seat - a number that easily lies within the error margin in national, let alone districtlevel, polling results (or extrapolations from previous elections). Therefore, due to the rising information requirements, more coordination failures and slower strategic adaptation may be expected with increasing district magnitude $(H 2)$. Early individual-level evidence of the mediating effect of district magnitude on strategic voting comes from Gunther (1989) who observes that voters with highly favourable attitudes toward the third- and fourth-place parties in large districts were about twice as likely to vote for them as sympathisers of those same parties in low-magnitude districts. ${ }^{6}$

Higher district magnitudes also complicate matters in another respect. In single-member districts, strategic coordination and voting always work to the detriment of the weak competitors. The same is not true for larger districts (Cox 1997: 116). In the above d'Hondt example, Party 3 is the runner-up for Party 1's third seat because it possesses the second largest electoral quotient in the final round of seat allocation. Hence, some instrumentally motivated supporters of Party 2, themselves with little chance of winning another seat for 
their party, should vote for either Party 1 or 3 to secure or contest Party 1's final seat. Of course, this would be a tough exercise since it requires voters to calculate the expected distribution of seats for all the parties to decide whether their party should be deserted, and if so, in favour of whom. Moreover, if too many supporters of Party 2 spent their supposed 'surplus' votes on a competitor, Party 2 might end up losing a seat. Therefore, there is less reason to expect a seat-winning party to be subject to strategic desertion than weak parties that do not win any seats $(H 3)$.

\section{Political conditions}

Starting with Sartori (1968), many scholars have stressed the vital importance of party system stability for successful strategic adaptation (e.g., Mainwaring 1998; Moser 1999). While this argument leaves a slight odour of simultaneity since party system stability may equally be considered the result of successful adaptation, continuity surely increases the amount of information previous elections (i.e., electoral histories) contain about future contests. In particular, we would expect candidates and parties that already ran, but went away empty-handed, at the preceding election to be deserted to a higher extent than competitors that gained representation at the previous election, current strategic incentives being equal ( $\mathrm{H} 4)$. In contrast, the information available on the electoral prospects of new competitors is much scarcer. Therefore, one would probably expect strategic desertion to operate less effectively if the candidate or party to be deserted were a first-time contender (H5). Lago's (2008) analysis of strategic coordination and voting in Spain indeed suggests that voters and party elites form expectations about the current electoral prospects of their preferred party based on their knowledge of whether or not this party won (a) seat(s) in their district at the previous election.

Beyond information requirements, strategic coordination and voting also demands that voters have strict preference orderings among the viable alternatives since otherwise it would be unclear in favour of whom to desert the most preferred but hopeless choice. This condition presumably is less frequently met in climates of stark political polarisation where hardly reconcilable camps face each other at elections, as is often the case, for example, in situations of intense ethnic conflict (e.g., Birnir 2009; Horowitz 1993). In particular, voters of radical ethnic parties may be expected to be largely indifferent between the alternatives, and thus to expressively support their candidate or party irrespective of their chances of winning just to demonstrate their discontent with the front-runners (H6). On the other hand, even those voters who prefer moderate parties may be limited in their choice sets when strong radical parties are present. Overall, strategic adaptation may be expected to 
advance from lower levels and much more slowly in deeply divided social contexts (H7). The subsequent section will show how the constructs introduced may be operationalised using election and survey data from Spain.

\section{Data}

Incentives for strategic behaviour emanate from where seats are allocated. Therefore, strategic adaptation to electoral systems is often best studied at the constituency level, where we have clearer theoretical expectations about (and operational expressions of) strategic behaviour. In this regard, Spain seems an ideal empirical case. Being one of the forerunners of what has become known as democracy's 'Third Wave', Spain held its first democratic national elections for 41 years in 1977. Even the Second Republic (1931-36) preceding the Franco-era had seen just three national elections, so it seems quite safe to proceed on the assumption that most party elites and voters had no previous experience with democratic elections in general, let alone the electoral system newly established in 1977 (see Gunther et al. 1986). Thus, we are able to observe the process of strategic adaptation from scratch. Since then, ten parliamentary elections have been held - a period that seems long enough in duration for strategic adaptation to materialise even under adverse conditions. Above all, however, it is Spain's peculiar electoral structure that makes it a particularly interesting case for the comparative study of strategic adaptation to new electoral institutions.

\section{Spain's electoral system}

Spain's parliament, the Cortes, consist of two chambers: the Congreso de los Diputados and the Senado. The 350 members of Congress are elected using what Monroe and Rose (2002) labeled a 'districted proportional representation' system that divides the country into 52 electoral districts which constitute the units of analysis of the present study. This makes for a panel of $52 \times$ $10=520$ district-election observations. The district magnitude varies according to population size from one seat in the Northern African exclaves of Ceuta and Melilla up to 35 seats in Madrid, with a median magnitude of five seats, thus encompassing a wide variety of presumptive constraints to strategic adaptation usually observed cross-nationally. Seats are allocated exclusively at the district level - that is, there is no higher electoral tier to compensate for wasted votes. As to the ballot structure, voters vote for lists (which may be joint lists composed of candidates from different parties), and they only have one vote, so they cannot vote for particular candidates within lists. Seats are distributed according to the d'Hondt method. Only lists with shares equal to or above 3 per cent of the district total are admitted to seat allocation. 


\section{Measuring strategic adaptation}

Strategic coordination and voting pertain to elite and voter behaviour. Therefore, some scholars maintain that the only way to study such behaviour is by focusing on individuals and not through aggregate data (e.g., Tsebelis 1986). However, strategic coordination and voting have distinctive implications readily observable from election results. An interesting statistic in this vein is Cox's (1994) second-to-first-loser's vote (SF) ratio. In the SMD case, its minimum of zero will obtain either if elites manage to coordinate on only two competitors before the election (i.e., there is no second loser to waste one's vote on) or if voters desert any candidates but the subsequent winner and his or her main challenger - according to Cox, a 'Duvergerian equilibrium' as this case supports Duverger's famous prediction that SMP systems favour twoparty competition. In contrast, its maximum of one will obtain if the expected vote shares of first and second losers are too close to decide which of the two to desert (a 'non-Duvergerian equilibrium', for that matter). Intermediate SF values, in turn, indicate that substantial shares of the electorate vote noninstrumentally, are indifferent between the viable alternatives, or disagree about which candidates are leading and trailing.

A remarkable feature of the $\mathrm{SF}$ ratio is its versatility across various electoral systems. For example, according to the d'Hondt formula used in Spain, the SF ratio simply refers to the ratio of the second losing quotient to the first losing quotient in the race for the final seat (see Note 5 and the related discussion and Cox 1997: 116). However, some authors (e.g., Gaines 1999) criticise the SF ratio for wrongly indicating non-Duvergerian equilibria in lopsided elections. To see this, consider an SMD with three candidates receiving 90,5 and 5 per cent of the votes. Indeed, it seems a bit odd to interpret this as an instance of a nonDuvergerian equilibrium ( $\mathrm{SF}$ ratio $=5 / 5=1$ ) where supporters of the secondand third-place finisher had difficulties in deciding which of the horses to back. Rather, the landslide victory of the winner seems to have squeezed all of the remaining vote shares close to equality - a tendency that is probably further exaggerated by instrumental supporters of both the first and the second loser who deserted their preferred candidate, not in favour of a more viable competitor, but in favour of abstention. A slight modification of the SF ratio accommodates such situations: the minimum of the first-loser's-to-(last)-winner's ratio and the second-to-first-loser's ratio $(\mathrm{mSF}$ ratio $=\min (5 / 90,5 / 5)=0.05)-$ that is, the district-level expectation of voters deserting their preferred candidate or party in favour of more viable alternatives (or abstention) would either be a sharp decline in the distribution of votes between the first and second loser or, in lopsided elections, already between the winner and the first loser, as indicated by an $\mathrm{mSF}$ value close to zero. In neck-and-neck races between (last) winner, 
first and second loser where instrumental voters have no incentive to desert their preferred choice (i.e., a truly non-Duvergerian equilibrium), the mSF ratio still assumes values close to unity. ${ }^{7}$

Thus, the aggregate implication of elites and voters behaving instrumentally would be a possibly bimodal distribution of mSF values with modes close to zero and unity. However, while both boundary points indicate that few votes are wasted on hopeless choices, non-Duvergerian equilibria (i.e., mSF values close to 1) are not necessarily tantamount to successful strategic coordination. To see this, consider an SMD with two candidates from the left receiving 33 per cent each, and a right-wing candidate who wins the seat with 34 per cent of the votes - obviously an instance of a non-Duvergerian equilibrium and a fatal strategic failure on the part of the left. Therefore, unambiguous indication of strategic adaptation is only to be found in a shift of the distribution of $\mathrm{mSF}$ values over subsequent elections towards the Duvergerian pole (i.e., mSF ratios close to zero). ${ }^{8}$

Figure 1 presents the distributions of modified SF ratios across the 52 Spanish districts, 1977-2008. In line with Cox's (1997: 115-117) analysis of the Spanish case, there is no evidence of strategic desertion of trailing parties in the first four elections, 1977-1986. From 1989 on, however, instances of nearly Duvergerian equilibria accumulate and, as of 2000, they seemingly become the dominant pattern. García Viñuela and Artés (forthcoming) add some individual-level support for the observed Duvergerian shift over the most recent three elections. In particular, they demonstrate that the defection rates among supporters of the Izquierda Unida, which is traditionally the major victim of strategic desertion (also see Gunther 1989; Lago 2008), increased from 12 to 33 per cent from 2000 to 2008 . While this offers some tentative evidence of strategic adaptation, the question of how quickly elites and voters learn under what structural and situational conditions continues to be open to empirical scrutiny.

\section{Party list features}

In line with the measure of strategic adaptation, party list features pertain to district contests and thus do not cover all the parties competing. Following the rationale underlying the modified SF ratio, the first list to be strategically deserted is the one with the second losing quotient at the final round of seat allocation, or, when voters expect a clear-cut election outcome, the first losing quotient. ${ }^{9}$ It has been hypothesised that the party possessing this relevant quotient $(\mathrm{RQ})$ will be subject to strategic desertion to a lesser extent if that party (H3) already won (a) seat(s) in the respective district in the current Congress Election (in that case, $\mathrm{RQC}=1$, otherwise 0 ); (H5) is a first-time 


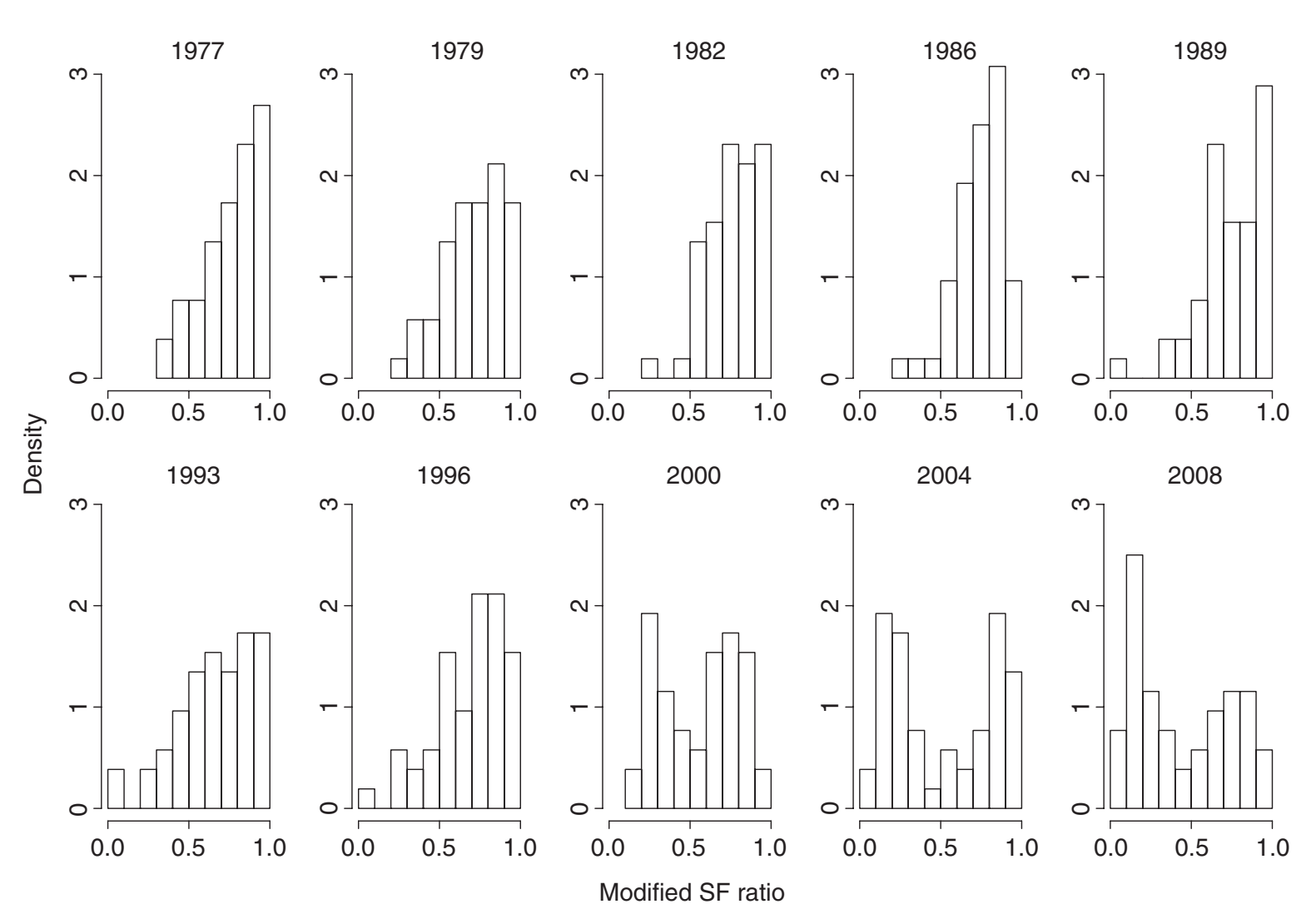

Figure 1. Distribution of modified SF values across 52 electoral districts, Spanish Congress elections, 1977-2008. 
competitor $(\mathrm{RQF}),{ }^{10}$ or $(\mathrm{H} 6)$ is an ethnic party $(\mathrm{RQE})^{11}$ and to a higher extent if that party (H4) already competed but went away empty-handed at the previous election in that district (RQP).

\section{District magnitude}

As mentioned, district magnitude in Spanish Congress elections ranges from 1 to 35 , with a median magnitude of five seats. For reasons that will become obvious in the subsequent modeling section, district magnitude is treated here as a time-invariant district characteristic. However, in 22 instances, the number of seats per district was adjusted to reflect changing shares of electoral population. Therefore, the median magnitude $(\mathrm{M})$ over the period of examination is used as a stable district feature. ${ }^{12}$

\section{Ethnic conflict}

While the at times violent Basque nationalism is probably the most apparent expression of ethnic antagonism in Spain, significant regional tensions also occur in other areas, such as Catalonia, the Canary Islands, Navarre and Galicia. In order to capture the subjective dimension constitutive of ethnic identity, aggregated survey data from Lago and Montero (2009: Table 4) are used. In particular, the intensity of ethnic conflict (EC) is measured as the average of the proportions of respondents per Autonomous Community identifying themselves as 'only regional' or 'more regional than Spanish' in election years between 1979 and $2004 .{ }^{13}$ Strength of regional identity varies, with an average of 0.19, from 0.49 in the Basque electoral districts to 0.04 in Castile-La Mancha, together with Madrid the historical birth place of the Spanish national state. According to $H 7$, a negative relationship between ethnic conflict and levels and rates of strategic adaptation is expected.

\section{A latent curve model of strategic adaptation}

The (modified) SF ratio is a relatively sensible aggregate measure of strategic behaviour, yet how to empirically model this quantity is debatable. In Duvergerian and non-Duvergerian equilibria, the distribution of the ratios will be heavily skewed; if both equilibria occur, the distribution will even be bimodal, thus severely violating the distributional assumptions of standard statistical models. In an earlier attempt to model the SF ratio using district-level election data from Japan, Cox and Shugart (1996) split the distribution at an arbitrary point of 0.4 , and modeled the probability that the SF value is below that point 
using logistic regression. Obviously, this strategy does not use the available information efficiently.

A more flexible and informative choice for 0/1-bounded scales with heavy skew and potential bimodality is the Beta distribution (Paolino 2001; Smithson $\&$ Verkuilen 2006). In its conventional formulation, the Beta distribution has two shape parameters, $\omega$ and $\tau$, with $\omega$ pulling density toward 1 and $\tau$ pulling density toward 0 . Different combinations of these can produce a large variety of distributional shapes, including bimodality at the poles. However, shape parameters are difficult to interpret in terms of conditional expectations, $E$. Therefore, an alternative parametrisation that translates $\omega$ and $\tau$ into a mean parameter, $\mu$, and a precision parameter, $\pi$, is commonly used for beta regression. Accordingly, $\mathrm{mSF}$ ratios are assumed to be beta-distributed, conditional on a vector of covariates, $\mathbf{X}$ :

$$
\operatorname{mSF} \mid \mathbf{X} \sim \operatorname{Beta}(\underbrace{-\phi \mu(\mathbf{X})}_{\omega}, \underbrace{-\phi(1-\mu(\mathbf{X}))}_{\tau})
$$

To form a regression model, Smithson and Verkuilen (2006) choose the logit link for the mean parameter,

$$
E(\mathrm{mSF} \mid \mathbf{X})=\mu=\frac{\exp (\beta \mathbf{X})}{1+\exp (\beta \mathbf{X})}
$$

to ensure that $\mu$ lies on the open unit interval. To model the precision parameter as a function of covariates, $\mathbf{Z}$, Smithson and Verkuilen use the log link,

$$
\phi=\exp (-\delta \mathbf{Z})
$$

in order to constrain the conditional variance of $\mathrm{mSF}$,

$$
\operatorname{Var}(\mathrm{mSF} \mid \mathbf{X})=\frac{\mu(1-\mu)}{1+\phi}
$$

to be positive.

However, the focus of this study is dynamic rather than static. In order to model district-specific patterns of change, a random coefficients, latent curve approach is adopted (for a recent overview, see Cudeck \& Harring 2007). The idea behind this approach is to define the process of change for each individual constituency, yet to relate district-level patterns of change to the mean trajectory of the population of districts. With this in mind, the simple beta regression in Equations 2 and 3 is reconceptualised as a hierarchical model with election terms $t=1, \ldots, 10$ at level one grouped within districts $i=1, \ldots, 52$ at level two. The level- 1 model includes a district-specific intercept, $\beta_{0 i}$, the time-varying 
covariates (RQC, RQP, RQF, RQE) and their regression weights, plus a linear election term scale, $\mathrm{T}$, again with district-specific coefficients, $\beta_{1 i}{ }^{14}$

$$
\begin{gathered}
\operatorname{logit}\left(\mu_{i t}\right)=\beta_{0 i}+\beta_{1 i} \mathrm{~T}_{i t}+\beta_{2} \mathrm{RQC}_{i t}+\beta_{3} \mathrm{RQP}_{i t-1}+\beta_{4} \mathrm{RQF}_{i t}+\beta_{5} \mathrm{RQE}_{i t} \\
\log \left(\phi_{i t}\right)=-\delta_{0}
\end{gathered}
$$

where $\delta_{0}$ is the intercept of the dispersion submodel in Equation $3 .{ }^{15}$ The $\beta_{1 i}$ parameters can be interpreted as district-specific rates of strategic adaptation: negatively signed estimates would indicate a reduction of $\mathrm{mSF}$ values over time, with estimates of higher magnitude indicating faster reduction. For technical reasons (i.e., to speed up convergence at the estimation stage), $T$ has been mean-centred to range from -4.5 in 1977 to 4.5 in 2008 . Therefore, the estimated district intercepts, $\beta_{0 i}$, can be interpreted as the (logit of the) expected $\mathrm{mSF}$ value amidst the time scale (i.e., at mid-term of the legislative period 1989-1993), with the time-varying covariates also being zero (see Stoel \& Van den Wittenboer 2003).

Finally, at level 2, $\beta_{0 i}$ and $\beta_{1 i}$ are modeled as functions of the contextual features that constitute the focus of interest of this study: the (log of) median district magnitude, $\mathrm{M},{ }^{16}$ and the intensity of ethnic conflict, EC:

$$
\begin{array}{ll}
\beta_{0 i}=\gamma_{00}+\gamma_{01} \log \left(\mathrm{M}_{i}\right)+\gamma_{02} \mathrm{EC}_{i}+u_{0 i}, & u_{0 i} \sim N\left(0, \sigma_{0}^{2}\right) \\
\beta_{1 i}=\gamma_{10}+\gamma_{11} \log \left(\mathrm{M}_{i}\right)+\gamma_{12} \mathrm{EC}_{i}+u_{1 i}, & u_{1 i} \sim N\left(0, \sigma_{1}^{2}\right)
\end{array}
$$

where the $\gamma$ 's are parameters to estimate, and $u_{0 i}$ and $u_{1 i}$ are district-level error terms assumed to be multivariate normally distributed with variances $\sigma_{0}^{2}$ and $\sigma_{1}^{2}$ and correlation $\rho$. If the theoretical propositions held, all the $\gamma$-estimates would be positive since larger as well as more conflicted districts should, on average, adapt more slowly and have higher $\mathrm{mSF}$ values in the middle of the time scale. That way, the level-2 model reflects district heterogeneity in general adaptive tendencies, while the level- 1 model accounts for eventual interim deviations from these broader developments. When presenting statistical results in the subsequent section, the two second level equations will be labeled the 'Beta- 0 equation' and the 'Beta- 1 equation', respectively. Bayesian methods with non-informative priors have been used for parameter estimation (see the Online Appendix for details).

\section{Results}

Figure 2 displays the medians of the model parameters' posterior probabilities and their 95 per cent confidence intervals. ${ }^{17}$ The null model (Model 0) contains only the random district intercepts, $\beta_{0 i}$, and term slopes, $\beta_{1 i}$, plus the dispersion 


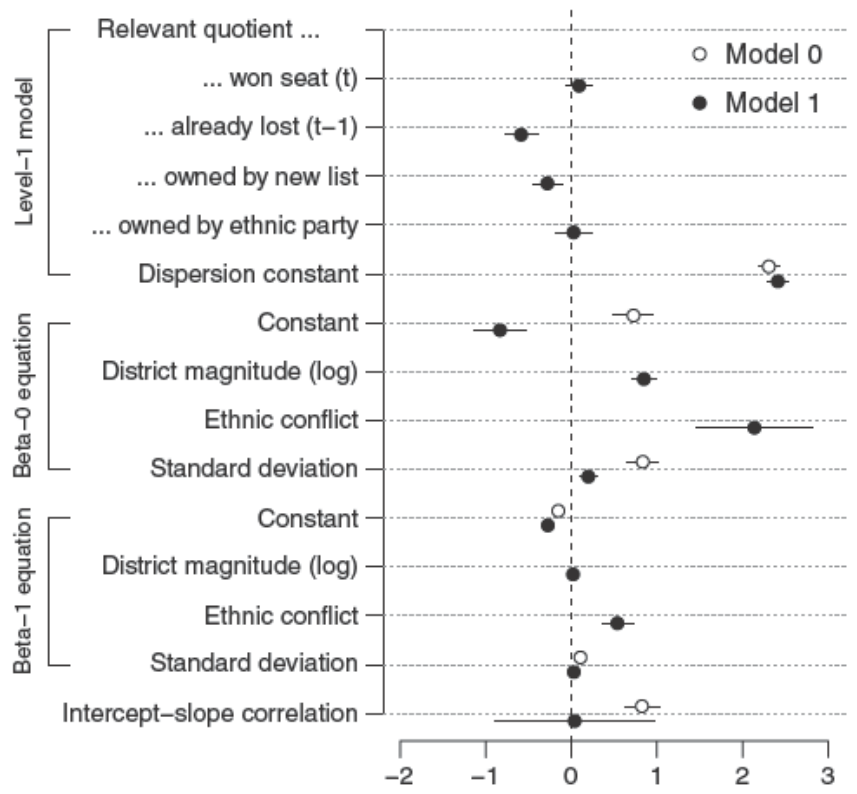

Figure 2. Estimates from the random coefficients beta regressions of modified SF ratios: Medians and 95 per cent credible intervals of the posterior probabilities.

constant, $\delta_{0}$, and thus permits the evaluation of the appropriateness of the simple unconditional model of strategic adaptation depicted in $H 1$. Indeed, the median $\gamma_{10}$ estimate is negative and significantly different from zero, indicating that the mean trajectory of the district population has tended toward smaller $\mathrm{mSF}$ values over time. In other words, voters in a 'typical' district have increasingly learned to avoid wasting their votes on party lists relatively hopeless of winning a(nother) seat, and have thus gradually moved party competition toward Duvergerian equilibria. However, as the estimates of $\sigma_{0}$ and $\sigma_{1}$ suggest, both random intercepts and term slopes vary significantly across districts and are almost perfectly correlated $(\rho=0.81)$ - that is, levels and rates of adaptation differ across districts, and high (interim) $\mathrm{mSF}$ values regularly coincide with slower adaptation rates. Therefore, an unconditional model of strategic adaptation seems too limited.

Model 1 additionally includes the covariates that may account for these differences. Considering the level- 1 model, strategic desertion obviously is particularly stark when the party possessing the largest quotient to be defected by instrumental voters already went away empty-handed at the previous election in the district, which strongly corroborates the importance of electoral histories as information sources (H4). Also in line with the expectations, ethnic 
parties possessing the relevant quotient tend to be less frequently deserted than other parties (H6). However, this effect is not significant at conventional levels. Contrary to the theoretical predictions, first-time competitors occupying the relevant quotient are deserted to a significantly higher extent than parties that have stood for election before (H5). An ad hoc interpretation of this finding may be that the willingness to run a second time is indicative of a core of loyal supporters whose motivations are not short-term instrumental. ${ }^{18}$ Another counterintuitive finding is that in cases where otherwise seat-winning parties possess the relevant electoral quotient, these tend to be deserted to a greater extent than parties that do not win any seats, although the respective coefficient, $\beta_{2}$, is again not significantly different from zero at the 95 per cent level $(H 3)$.

At the second level, the estimated district intercepts turn out to be significantly and positively related to $(\log )$ district magnitude and the intensity of ethnic conflict, indicating that larger districts and districts with higher levels of ethnic conflict, on average, had higher interim mSF values (H2, H7). As opposed to ethnic conflict, however, district magnitude is not significantly related to rates of adaptation, $\beta_{1 i}$. To illustrate the fit of the second-level model, Figure 3 plots the estimated intercepts and term slopes versus (log) district magnitude and the ethnic conflict measure, along with the level-2 regression lines. As to the estimated intercept regression, the linear fit with (log) district magnitude is impressive. In contrast, the slope relating district magnitude with the rates of adaptation is almost flat, with tremendous scatter. The reverse pattern holds in connection with the ethnic conflict measure: while the intensity of ethnic conflict seems to determine the magnitude of the term slope (i.e., the adaptation rate) almost perfectly, there is more uncertainty regarding the effect on the estimated district intercepts. ${ }^{19}$

In other words, elites and voters in smaller districts are obviously confronted with easier coordination tasks, and therefore generally exhibit a stronger proclivity toward strategic desertion than voters in larger districts. In fact, the observed and predicted patterns of change in $\mathrm{mSF}$ ratios for the 52 Spanish districts (see Figure 1 in the Online Appendix) tend to support Cox and Shugart's (1996) rule of thumb that electoral coordination fades out quickly as the district magnitude rises above five, although there are also some considerably larger districts with sizeable indication of strategic desertion. Yet while district magnitude seems to set the upper limit of learning, it has no appreciable effect on the speed of adaptation which, in turn, seems to almost fully be determined by the degree of ethnic conflict.

Figure 4 translates the effects implied by the model parameters back from the logit scale to the original metric of the dependent variable, and plots predicted and observed district-specific trajectories using selected constituencies 

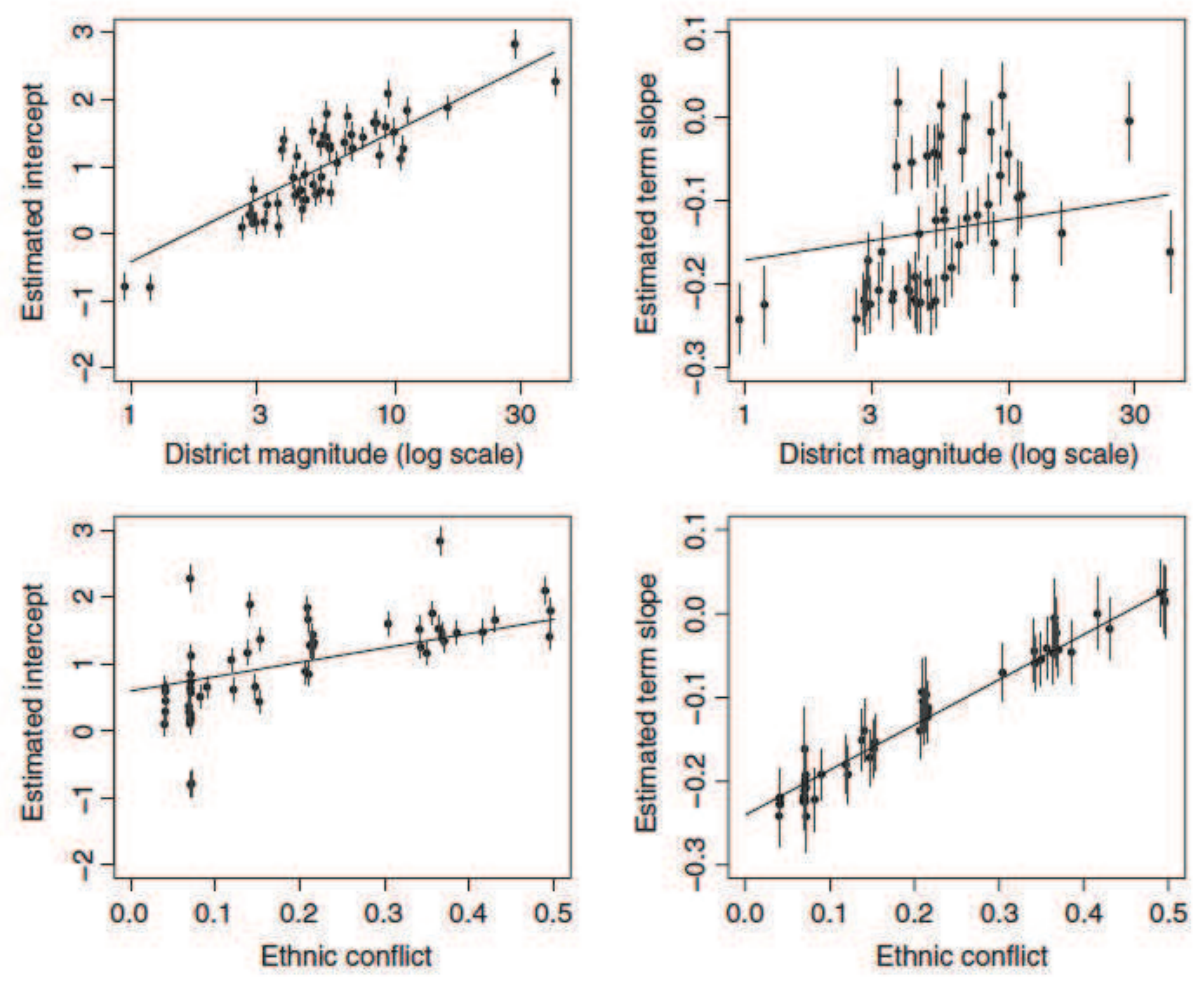

Figure 3. Estimated district intercepts, $\boldsymbol{\beta}_{0 i}$, and term slopes, $\boldsymbol{\beta}_{i i},( \pm 1$ standard error) plotted versus log district magnitude and intensity of ethnic conflict, along with the level-2 regression lines.

of varying magnitudes and different levels of ethnic conflict. Predictions are based on the latent curve model of strategic adaptation including all the covariates plus random effects ('Model 1'). Overall, the fit of Model 1 to the data is quite impressive. To give an intuitive idea, the squared correlation between observed and predicted $\mathrm{mSF}$ values is $0.76 .{ }^{20}$ Moreover, the introduction of the covariates has largely eliminated the estimated intercept and slope variance, as well as their covariance - that is, the substantive explanations offered account for most of the differences in levels and rates of strategic adaptation observable across electoral districts.

\section{Discussion}

This study investigated to what extent, how quickly and under what conditions voters and elites manage to adapt to newly established electoral systems 

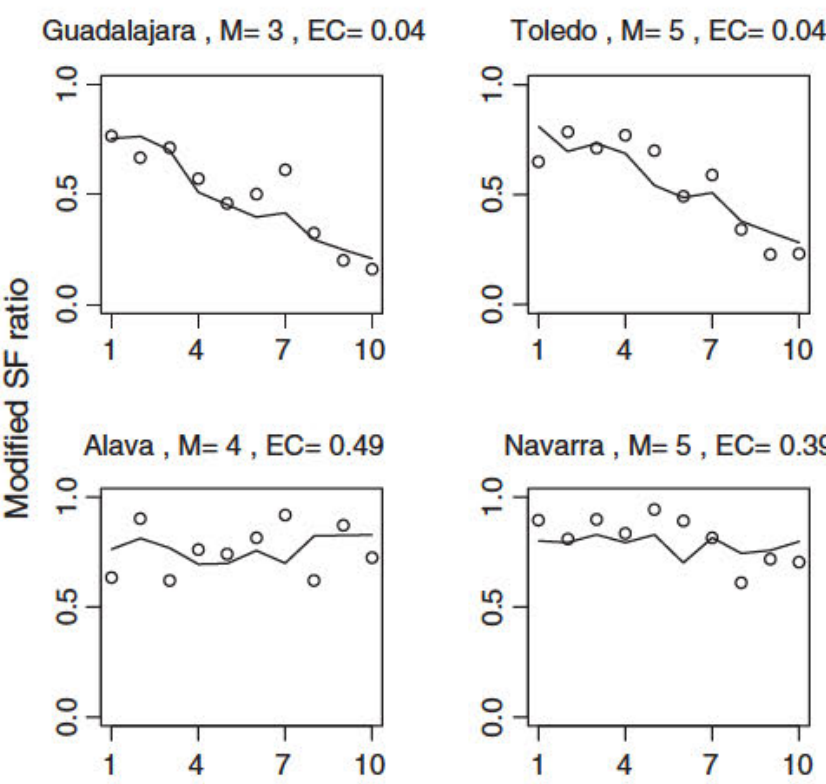

Murcia , $M=9, E C=0.07$

Madrid , $\mathrm{M}=33.5, \mathrm{EC}=0.07$
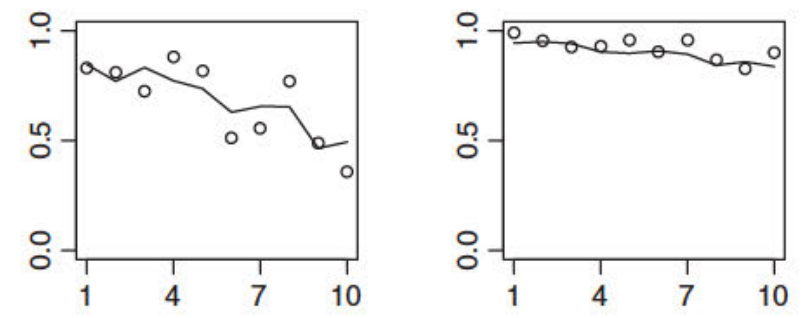

Navarra , $M=5, E C=0.39$

Vizcaya , $\mathrm{M}=9.5, \mathrm{EC}=0.49$

Barcelona , $\mathrm{M}=32, \mathrm{EC}=0.37$
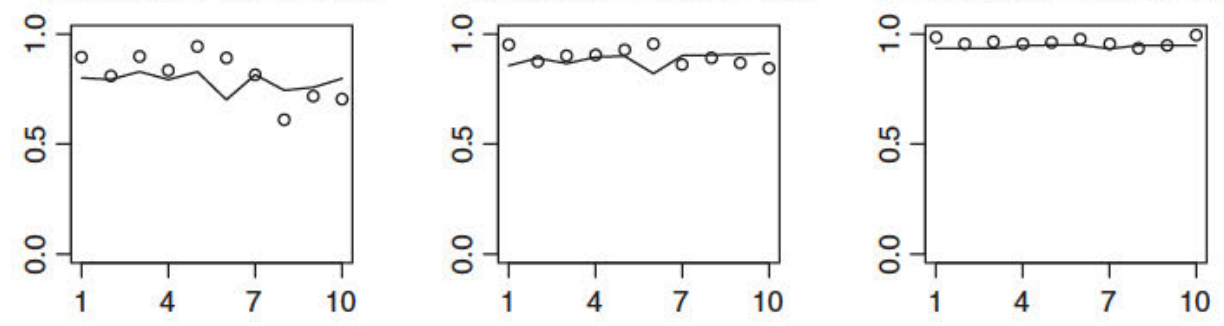

\section{Election term}

Figure 4. Observed (circles) and predicted patterns of change (lines) in modified SF ratios for selected districts. The upper (lower) panels refer to districts with low (high) levels of ethnic conflict (EC). Median district magnitude (M) increases from left to right. Observed and predicted trajectories for all the 52 districts are given in the Online Appendix. 
using district-level election data from Spain. Due to its longer democratic experience, its variable electoral structure and its strong regionally based cleavages, Spain is a particularly well-suited case to test propositions about the interplay between social structure and institutions in shaping political behaviour. ${ }^{21}$ Results from a latent-curve model indicate, first, the importance of continuous electoral histories as information sources for voters learning not to waste their votes; second, the dampening effect of rising district magnitude on the extent of strategic coordination; and third, the problems ethnic conflicts pose for successful adaptation over time. Considering that many of the countries from the most recent wave of democratisation in Central and Eastern Europe are deeply divided along ethnic lines, this last finding is probably the most alarming.

All the more important it is to further scrutinise why strategic adaptation fails in such conflicted environments. One potential explanation offered - that voters of 'hard core' ethnic parties are largely indifferent between the viable alternatives, and vote for their parties irrespective of their chances of winning received only weak empirical support. One reason for this may be that the inclusion criteria for parties being counted as ethnic parties have been rather generous, covering both radical secessionist and moderate regionalist parties that have been coalition partners to major national parties (see Table 1 in the Online Appendix, and also Birnir 2009). In any case, a promising direction for future theoretical and empirical work would be to more directly address the role of intensely held preferences in such repeated coordination games (see Cox 1997: 234-236). At the same time, the finding that ethnic tensions hamper strategic adaptation may explain a longstanding empirical puzzle - namely why Spanish Congressional elections persistently exhibit higher levels of disproportionality than other national elections held under PR rules (see Taagepera 2007: $54-68){ }^{22}$

In contrast, the common finding that strategic desertion fades out quickly as district magnitude rises is probably less worrisome than it might appear at first glance (after all, most recent democracies have established relatively 'permissive' electoral systems with large constituencies, see Shvetsova 1999). As Cox (1997: 226-237) demonstrates, local coordination failures are less consequential for the representational performance of parliaments in PR as opposed to SMP electoral systems.

The explicit consideration of time is, perhaps, the second major contribution of this study, as this factor has been largely neglected in the previous literature on the interaction between electoral systems and social structure in shaping political outcomes (e.g., Ordeshook \& Shvetsova 1994; Cox 1997: 203-221). Indeed, many scholars of electoral systems will probably be perplexed by how slowly strategic adaptation has proceeded in the Spanish case 
even under relatively favourable institutional and political conditions (see Figure 1 in the Online Appendix) since another frequently quoted rule of thumb maintains that two elections suffice for elites and voters to accustom themselves to new electoral institutions (Lijphart 1994).

That said, some qualifications are due. First of all, throughout the present analysis, the question of whether it is the voters or the elites that primarily (fail to) adapt has remained unanswered. As Cox (1997: 148) puts it, 'there are many instrumentally rational agents in elections - candidates, activists, contributors - and all of them may respond in ways that overwhelm or accentuate the strategic responses of voters' evident in election results. However, in the present case, the number of competitors has, irrespective of district magnitude, almost doubled over the period of study. For example, in the founding election of 1977, the average number of lists entering the race in the two SMDs was five. In 2008, it was 9.5. The largest district of Madrid had 18 lists competing in 1977 and 37 in 2008. This observation fosters speculation that the secular trend toward adaptation observed in many districts actually traces back to strategic voting, not coordination among elites (also see Gunther 1989).

Second, it has been argued that, for both theoretical and measurement reasons, strategic adaptation is best studied at the constituency level. This choice, however, has not come free of charge. In particular, national-level factors previously theorised and found to affect strategic coordination, such as the presence of concurrent presidential elections or higher-tier corrections for wasted votes (see Cox 1997: 209-213), could not be considered. Multi-country district-level designs would thus offer a fruitful extension to the present work (e.g., Selb 2009).

Finally, this study used a variant of Cox's SF ratio to measure strategic adaptation. As a drawback, the modified SF measure is, like the SF ratio, insensitive to ideological considerations - that is, it looks only at vote shares based on first place preferences (or rather first-place preferences subject to some unknown level of strategic voting), not at full voter preference rankings, which are invisible, at least from official election statistics. Clearly, strategic incentives emanate both from the expected distribution of votes and the individual preference orderings among the alternatives. However, as opposed to conventional wasted vote measures which are summations across parties (e.g., any vote which is not for an elected candidate or party; see Tavits \& Annus 2006; Van der Weyden \& Meuleman 2008), SF and mSF ratios at least allow one to specify in a party-specific manner the ideological conditions under which strategic desertion is to be expected (see H6). Extensions, for example, in terms of the minimum ideological distance to one of the viable alternatives, are in principle possible, though we lacked the information 
necessary to implement them. Nevertheless, further conceptual and empirical effort is surely needed to arrive at even more sensitive aggregate measures of strategic voting and wasted votes.

\section{Acknowledgements}

A previous version of this article was presented at the 2009 ECPR General Conference in Potsdam, panel 'Context effects in comparative studies of party choice'. I am grateful to the participants, to Bernard Grofman and Ignacio Lago, as well as the reviewers and editors for their helpful comments. I thank Jay Verkuilen for providing WinBUGS code for validating mixed beta regression models. I also thank Jojo Duin for excellent research assistance, Naomi Bosler for language editing, and Birgit Jacob for proofreading. An Online Appendix to this article is available at: www.polver.uni-konstanz.de/en/selb/ publications/.

\section{Notes}

1. Also see Benoit (2002) for a number of instances of SMP elections producing almost perfect proportionality between the parties' vote and seat shares.

2. Indeed, many decision-theoretic models of strategic voting are either explicitly static, or hardly tractable as to their comparative dynamics. Many game-theoretic models, on the other hand, start from the assumption of fully informed voters, and thus preclude learning processes. For a critique of formal models of strategic voting for their negligence of dynamics, see Clough (2007). For an explicitly dynamic exception, see Fey (1997). Also see Taagepera (2002) for some powerful arguments in favour of a developmental perspective on electoral coordination.

3. Recent takes on strategic voting also investigate how distinctly national factors - that is, expected coalition composition - affect voter choice (e.g., Bargsted \& Kedar 2009; Blais et al. 2006). Nevertheless, ensuring that one's vote is not wasted on a hopeless district candidate or party is definitely a precondition for exerting (a whatsoever minimal) influence on the formation of national government.

4. Also see Forsythe et al. (1993) for some impressive experimental evidence of the importance of electoral histories for successful strategic coordination in multiparty SMP elections.

5. According to the d'Hondt method of seat allocation, the vote share of each (seatwinning) party is successively divided by a series of divisors 1,2,3 and so on. Seats are allocated one at a time to the party that achieves the highest quotient. In the present example, Party 1 gets the first seat (since 50/1>35/1>15/1), Party 2 the second (35/ $1>50 / 2>15 / 1)$, Party 1 the third $(50 / 2>35 / 2>15 / 1)$, Party 2 the fourth $(35 / 2>50 / 3>15 /$ $1)$, and Party 1 the fifth and final seat $(50 / 3>15 / 1>35 / 3)$.

6. More recent survey-based support for this conjecture is to be found in García Viñuela and Artés (forthcoming) and Lago (2008). 
7. In 75 per cent of our district-election observations, the mSF ratio actually is the SF ratio. Interestingly, the proportion of cases in which the second-to-first-loser's ratio is smaller than the first-loser's-to-last-winner's ratio has increased over time, from 63 per cent in 1977 to 92 per cent in 2008, indicating that Spanish Congress elections have become more competitive at the district level.

8. Also see Fey (1997) who formally demonstrates how information about the viability of candidates in SMP elections helps voters to successively coordinate on Duvergerian, and to eliminate non-Duvergerian outcomes.

9. To be sure, the quotient subject to strategic desertion so defined does not necessarily belong to the party whose supporters have the strongest incentives to defect; it simply is the largest quotient to be defected by instrumental voters.

10. It should be noted that all the lists competing in the first election of 1977, refoundations such as the Centro Democrático y Social (formerly Unión de Centro Democrático), party mergers such as the Partido Popular (formerly Centro Democrático y Social, Alianza Popular, Partido Demócrata Popular, and Partido Liberal) and joint lists of existing parties have also been coded as new lists at their first appearance.

11. 'Ethnicity' is very broadly conceived of as a group's 'self-identification around a characteristic that is very difficult or even impossible to change, such as language, race, or location' (Birnir 2009: 66). Coded here are parties promoting more national autonomy for their region. See the Online Appendix for details.

12. An additional variable indicating changes in magnitude compared to the previous election has been incorporated in preliminary empirical analyses, but excluded from the final model since it significantly affected neither modified SF ratios nor the relationship between dependent and other independent variables. Detailed results are available on request from the author.

13. Unfortunately, district-level data are not readily available. Therefore, regional identity has to be assumed constant across districts within Communities. There are 17 Autonomous Communities comprising one to eight electoral districts, with an average of three. Information loss due to temporal aggregation is minimal because regional identity so defined is largely stable over time (see Lago \& Montero 2009). See the Online Appendix for details.

14. Alternative, nonlinear specifications of the time scale turned out to be empirically inferior (see Figure 3).

15. Of course, one could also model dispersion as a function of covariates or even conceive of $\delta_{0}$ as a district-specific parameter. However, preliminary analyses indicated that letting $\delta_{0}$ vary across districts did not substantially improve the model fit.

16. Although Cox (1997) observes that strategic voting fades out quickly as M rises, neither theory nor previous empirics are specific about the functional form of this decay. Hence, alternative specifications have been tested: $M, \log (M)$, and $1 /(M+1)$, of which $\log (M)$ provided the best fit to the data.

17. Kastellec and Leoni's (2007) R-code has been modified to make this coefficient graph.

18. I am grateful to Richard Katz for this pointer.

19. One may also have conjectured that the effects of ethnic conflict and district magnitude were mutually dependent. If this was the case, however, we would probably have expected clearer evidence of heteroscedasticity in Figure 3. Moreover, an alternative model including an interaction of both factors did not prove superior in terms of model fit.

20. See Smithson and Verkuilen (2006) for why pseudo $R^{2}$ is actually inappropriate to assess model fit in this context. Alternative, more formal, but probably less intuitive fit statistics 
have been used (see Gelman \& Hill 2007:513-528), backing the mostly graphic evidence presented here. For example, the Deviance Information Criterion (DIC)—an estimate of the expected predictive error correcting for the effective number of parameters in Bayesian hierarchical models - is -684 for the empty model, and -754 for the model including covariates.

21. One may even add that the Spanish case is particularly conducive to disentangling the longstanding debate between sociologists and institutionalists on 'endogenous institutions' - that is, on whether institutions independently shape political outcomes, or merely reflect deeper social divides which themselves shape both institutional choice and political outcomes (e.g., Benoit 2002; Cox 1997: 13-27), since district magnitude in Congressional elections is determined by the size of the districts' electoral population, and size is probably unrelated to the socio-structural feature of interest. Indeed, district magnitude and levels of ethnic conflict correlate at 0.17 in our sample, which is not significantly different from zero at conventional levels.

22. I am grateful to an anonymous reviewer for this hint.

\section{References}

Bargsted, M.A. \& Kedar, O. (2009). Coalition-targeted Duvergerian voting: How expectations affect voter choice under proportional representation. American Journal of Political Science 53: 307-323.

Benoit, K. (2002). The endogeneity problem in electoral studies: A critical re-examination of Duverger's mechanical effect. Electoral Studies 21: 35-46.

Bielasiak, J. (2005). Party competition in emerging democracies: Representation and effectiveness in post-communism and beyond. Democratization 12: 331-356.

Birch, S. (2005). Single-member district electoral systems and democratic transition. Electoral Studies 24: 281-301.

Birnir, J.K. (2009). Ethnicity and electoral politics. Cambridge: Cambridge University Press.

Black, J. (1978). The multicandidate calculus of voting: Applications to Canadian federal elections. American Journal of Political Science 22: 609-638.

Blais, A. et al. (2006). Do voters vote for government coalitions? Testing Downs' pessimistic conclusion. Party Politics 12: 691-705.

Bohrer, R.E. (1997). Deviations from proportionality and survival in new parliamentary democracies. Electoral Studies 16: 217-226.

Clough, E. (2007). Strategic voting under conditions of uncertainty: A re-evaluation of Duverger's Law. British Journal of Political Science 37: 313-332.

Cox, G. (1994). Strategic voting equilibria under the single nontransferable vote. American Political Science Review 88: 608-621.

Cox, G. (1997). Making votes count: Strategic coordination in the world's electoral systems. Cambridge: Cambridge University Press.

Cox, G. \& Shugart, M.S. (1996). Strategic voting under proportional representation. Journal of Law and Economics 12: 299-324.

Cudeck, R. \& Harring, J.R. (2007). Analysis of nonlinear patterns of change with random coefficient models. Annual Review of Psychology 58: 615-637.

Dawisha, K. \& Deets, S. (2006). Political learning in post-communist elections. East European Politics and Societies 20: 691-728. 
Duch, R.M. \& Palmer, H.D. (2002). Strategic voting in post-communist countries. British Journal of Political Science 32: 63-91.

Fey, M. (1997). Stability and coordination in Duverger's Law: A formal model of preelection polls and strategic voting. American Political Science Review 91: 135-147.

Forsythe, R. et al. (1993). An experiment on coordination in multi-candidate elections: The importance of polls and election histories. Social Choice Welfare 10: 223-247.

Gaines, B. (1999). Duverger's Law and the meaning of Canadian exceptionalism. Comparative Political Studies 32: 835-861.

García Viñuela, E. \& Artés, J. (forthcoming). Strategic voting and effective representation thresholds: Evidence from three Spanish general elections. European Journal of Political Research.

Gelman, A. \& Hill, J. (2007). Data analysis using regression and multilevel/hierarchical models. Cambridge: Cambridge University Press.

Granados, F.J. (2005). Intertwined cultural and relational environments of organizations. Social Forces 83: 883-918.

Gschwend, T. (2007). Institutional incentives for strategic voting and party system change in Portugal. Portuguese Journal of Political Science 6: 15-31.

Gunther, R. (1989). Electoral laws, party systems and elites: The case of Spain. American Political Science Review 83: 835-858.

Gunther, R., Sani, G. \& Shabad, G. (1986). Spain after Franco: The making of a competitive party system. Berkeley, CA: University of California Press.

Horowitz, D.L. (1993). Democracy in divided societies. Journal of Democracy 4: 18-38.

Horowitz, S. \& Browne, E.C. (2005). Sources of post-communist party system consolidation: Ideology versus institutions. Party Politics 11: 689-706.

Kastellec, J.P. \& Leoni, E.L. (2007). Using graphs instead of tables in political science. Perspectives on Politics 5: 755-771.

Lago, I. (2008). Rational expectations or heuristics? Strategic voting in proportional representation systems. Party Politics 14: 31-49.

Lago, I. \& Montero, J.R. (2009). Coordination between electoral arenas in multilevel countries. European Journal of Political Research 48: 176-203.

Leys, C. (1959). Models, theories and the theory of political parties. Political Studies 7: 127-146.

Lijphart, A. (1994). Electoral systems and party systems: A study of twenty-seven democracies, 1945-1990. Oxford: Oxford University Press.

Mainwaring, S. (1998). Party systems in the Third Wave. Journal of Democracy 9: 67-81.

Monroe, B.L. \& Rose, A.G. (2002). Electoral systems and unimagined consequences: Partisan effects of districted proportional representation. American Journal of Political Science 46: 67-89.

Moser, R.G. (1999). Electoral systems and the number of parties in postcommunist states. World Politics 51: 359-384.

Moser, R.G. \& Scheiner, E. (2009). Strategic voting in established and new democracies: Ticket splitting in mixed-member electoral systems. Electoral Studies 28: 51-61.

Ordeshook, P.C. \& Shvetsova, O.V. (1994). Ethnic heterogeneity, district magnitude and the number of parties. American Journal of Political Science 38: 100-123.

Paolino, P. (2001). Maximum likelihood estimation of models with beta-distributed dependent variables. Political Analysis 9: 325-346.

Reed, S.R. (1990). Structure and behaviour: Extending Duverger's Law to the Japanese case. British Journal of Political Science 20: 335-356. 
Sartori, G. (1968). Political development and political engineering. In J.D. Montgomery \& A.O. Hirschman (eds), Public Policy. Cambridge: Cambridge University Press.

Selb, P. (2009). A deeper look at the proportionality-turnout nexus. Comparative Political Studies 42: 527-548.

Shvetsova, O. (1999). A survey of post-communist electoral institutions, 1990-1998. Electoral Studies 18: 397-409.

Shvetsova, O. (2002). Gaining legislative control through strategic district nomination: The case of the Russian left in 1995. Legislative Studies Quarterly 27: 635-657.

Smithson, M. \& Verkuilen, J. (2006). A better lemon squeezer? Maximum-likelihood regression with beta-distributed dependent variables. Psychological Methods 11: 54-71.

Stoel, R.D. \& Van den Wittenboer, G. (2003). Time dependence of growth parameters in latent growth curve models with time invariant covariates. Methods of Psychological Research 8: 21-41.

Taagepera, R. (2002). Designing electoral rules and waiting for an electoral system to evolve. In A. Reynolds (ed.), The architecture of democracy: Constitutional design, conflict management and democracy. Oxford: Oxford University Press.

Taagepera, R. (2007). Predicting party sizes: The logic of simple electoral systems. Oxford: Oxford University Press.

Tavits, M. (2008). On the linkage between electoral volatility and party system instability in Central and Eastern Europe. European Journal of Political Research 47: 537-555.

Tavits, M. \& Annus, T. (2006). Learning to make votes count: The role of democratic experience. Electoral Studies 25: 72-90.

Tsebelis, G. (1986). A general model of tactical and inverse tactical voting. British Journal of Political Science 16: 395-404.

Van der Weyden, P. \& Meuleman, B. (2008). Electoral systems and strategic learning in Spain and Portugal? The use of multilevel models. Acta Politica 43: 93-117.

Address for correspondence: Peter Selb, Department of Politics and Public Administration, University of Konstanz, D-78457 Konstanz, Germany. E-mail: peter.selb@uni-konstanz.de 